\title{
Discovery of Hepatitis C Virus: 2020 Nobel Prize in Medicine
}

Hemshankar Laugi ${ }^{1}$

\begin{abstract}
HIGHLIGHTS
Hepatitis C virus (HCV) accounts for hepatitis, cirrhosis, hepatocellular carcinoma, and liver transplantation. Every year, millions of people develop chronic liver diseases. This article provides novel insights into the major breakthroughs in the discovery of hepatitis C virus. 2020 Nobel Prize in Medicine was awarded to Michael Houghton, Harvey Alter, and Charles Rice for their outstanding contribution in the discovery of HCV. Also, this article deals with current findings, challenges, and future prospects in the diagnosis of HCV infection. DAA, along with protease inhibitors, is found to have higher SVR and is a promising drug to treat HCV infection. However, with regard to the emergence of resistance to DAAs, CRISPR-Cas can be the future technique in preventing resistance. Although the current knowledge of molecular mechanisms associated with $\mathrm{HCV}$ infection is insufficient, the better understanding of it provides better hope in the treatment of HCV.
\end{abstract}

\section{Definitions of Medical Terms Used}

Lymphoma: A cancer causing infection on lymphocytes.

Fulminant hepatitis: A decrease in the size of the liver accompanied even by the death of liver parenchyma with the onset of infection with hepatitis virus.

Transfection: The process of introducing nucleic acids into eukaryotic cells without using viral methods.

Huh-7 cells: A type of liver cells grown in the laboratory for research purposes.

Immunoscreening: A biomedical method that helps to detect a protein produced from a cloned gene after it undergoes transcription, followed by the translation process within the cell.

cDNA library: A group of only the genes that are encoded into proteins by an organism.

Sustained virologic response: Absence of any evidence of the presence of HCV in the blood of patients with chronic HCV infection after undergoing antiviral treatment.

Pegylated interferon: A covalent conjugate of recombinant interferon and polyethylene glycol, used as an antiviral and antineoplastic agent. Immunoelectron microscopy: A technique to localize ultrastructure antigens or antibodies in cells or tissues for the diagnosis of viral infections. Stellate cells: A major type of liver cell involved in liver cirrhosis.

\section{ABSTRACT}

Hepatitis C virus (HCV) accounts for hepatitis, liver cirrhosis, hepatocellular carcinoma, and liver transplantation. This virus is a single-stranded RNA virus that belongs to the Flaviviridae family. According to the WHO, about 71 million people have chronic HCV infections around the globe in 2020, and hence, it is a plague of humankind. The credit of discovery of HCV goes to Michael Houghton, Harvey Alter, and Charles Rice for which they are awarded 2020 Nobel Prize in Medicine. Their contribution has given better hope to mankind to cure HCV for the first time in the history. With the use of pegylated interferon and ribavirin jointly, higher SVR has been found comparatively, even in patients with chronic liver diseases. However, due to excessive pain tolerated by patients, interferon (IFN)-based therapy is rapidly being replaced with IFN-free DAA regimens. With the onset of resistance to DAA drugs, CRISPR-Cas system can be used to modify the viral genome to impair their ability to develop resistance. Keywords: Chronic hepatitis C, CRISPR-Cas system, DAA drugs, Hepatitis C virus, Pegylated interferon.

Euroasian Journal of Hepato-Gastroenterology (2020): 10.5005/jp-journals-10018-1326

\section{INTRODUCTION}

The hepatitis $C$ virus (HCV) is an enveloped, positive-sense singlestranded RNA virus belonging to the family Flaviviridae. This virus is proved to be a common cause of hepatitis C, liver cancer, and lymphomas in humans. ${ }^{1} \mathrm{HCV}$ is anticipated to be a leading cause of death in the world. There has been a rapid increase in the number of patients with chronic HCV infection. About 1200 acute HCV cases were reported in 2011 in the United States, which rose to around 3600 cases in 2018 after just a period of 7 years in a single developed country. Also, acute HCV cases are found to be highest in 65+ age-group whereas lowest in 0 to 19 age-group as shown in Table 1. Developing poor countries mostly in Asia and Africa have a higher number of cases of patients with acute HCV infection as compared to developed, industrialized nations in Europe and North
1Department of Biology, BKVM, Biratnagar, Morang, Nepal

Corresponding Author: Hemshankar Laugi, Department of Biology, BKVM, Biratnagar, Morang, Nepal, Phone: +977 9816768152, e-mail: laugi.hemshankar@gmail.com

How to cite this article: Laugi H. Discovery of Hepatitis C Virus: 2020 Nobel Prize in Medicine. Euroasian J Hepato-Gastroenterol 2020;10(2): 105-108.

Source of support: Nil

Conflict of interest: None

America. However, adequate data about HCV cases in developing countries are not available. ${ }^{2}$ According to WHO, approximately 399,000 people died of chronic HCV infection globally in 2016 


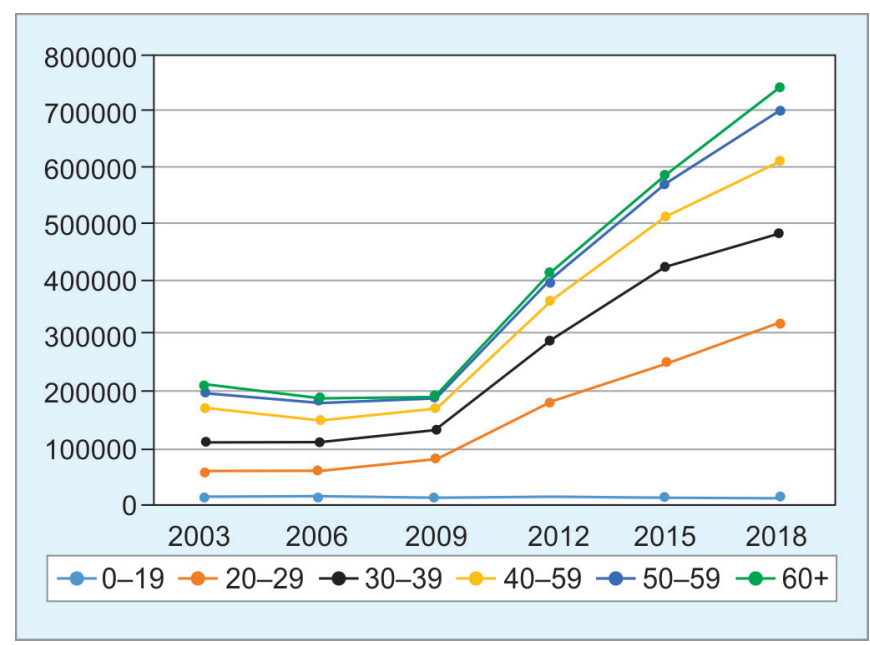

Fig. 1: HCV cases since 2003 in the United States (Source: https://www. cdc.gov/hepatitis/statistics/2018surveillance/HepC.htm\#Figure3.1) ${ }^{3}$

only and it is estimated that 71 million people have chronic HCV infections around the globe in 2020 (Fig. 1).

\section{Materials and Methods}

Databases, such as PubMed, Google Scholar, and ResearchGate, were searched thoroughly to collect the data on the discovery of hepatitis $C$ virus, current findings, challenges, and future prospects in the treatment of HCV infection. MeSH subject headings like hepatitis $C$ virus, pegylated interferon, DAA combined therapy, and serum biomarkers were used to collect relevant data. After in-depth study of the selected articles, appropriate information is selected to be included in this article. Finally, it was read and approved by the author.

\section{Discussion}

\section{History of Discovery of HCV}

The discovery of HCV has led to a major breakthrough in the treatment of liver cancer. The contribution of Michael Houghton, Harvey Alter, and Charles Rice was remarkable in the discovery of HCV. Hence, they are awarded 2020 Nobel Prize in Medicine. ${ }^{4}$ The disease can be cured for the first time in history, raising hope to save millions of people with acute HCV.

The discovery of hepatitis was initiated in 1950 with the identification of infectious and serum hepatitis. Later on, hepatitis A virus (HAV) was found to be the cause of the infection by Dr. Stephen Feinstone et al. ${ }^{5}$ and hepatitis B virus (HBV) was found to be the cause of it by Dr. Baruch Blumberg and colleagues. ${ }^{6}$ But, the existence of hepatitis $C$ virus (HCV) was still not recognized until 1975. Dr. Stephen Feinstone et al. figured out that most cases of transfusion-associated hepatitis were not associated with hepatitis A virus or hepatitis B virus (HBV) infections, and for the timing, they named the virus as NANBH. ${ }^{7}$ The number of cases of transfusion-related hepatitis was diminished with the discovery of HBV. However, Dr. Harvey J. Alter and his colleagues figured out that all the transfusion-related hepatitis cases were not similar to the cases of HBV. They even successfully demonstrated HAV not to be the cause of these unexplained cases. This drew their attention toward the patients receiving blood transfusion developing chronic hepatitis due to an undiscovered infectious
Table 1: Breakthrough in HCV research

\begin{tabular}{|c|c|c|}
\hline Date & Major breakthroughs & References \\
\hline 1963 & $\begin{array}{l}\text { Nobel Prize winner Baruch S. Blumberg } \\
\text { reported a new antigen named Australia } \\
\text { antigen (AuAg) }\end{array}$ & [9] \\
\hline 1967 & $\begin{array}{l}\text { Discovery of hepatitis B virus by } \\
\text { Dr. Baruch Blumberg }\end{array}$ & {$[10]$} \\
\hline 1975 & $\begin{array}{l}\text { New hepatitis agent NANBH recognized } \\
\text { with the advent of specific serological } \\
\text { tests for HAV and HBV }\end{array}$ & [11] \\
\hline 1977 & $\begin{array}{l}\text { Stephen Feinstone at the NIH and his } \\
\text { colleague Kapikian identified a new } \\
\text { agent in stool specimen of HAV out- } \\
\text { breaks leading to the discovery of HAV } \\
\text { vaccine }\end{array}$ & [12] \\
\hline 1978 & NANBH transmitted to chimpanzee & [13] \\
\hline 1985 & $\begin{array}{l}\text { George Kuo advocated the application } \\
\text { of immunoscreening cDNA cloning } \\
\text { strategy to NANBH }\end{array}$ & [11] \\
\hline 1989 & $\begin{array}{l}\mathrm{HCV} \text { cloned from chimpanzee serum } \\
\text { and discovery of } \mathrm{HCV}\end{array}$ & {$[12,13]$} \\
\hline 1990 & $\begin{array}{l}\text { HCV antibody assay developed to screen } \\
\text { donor blood } \\
\text { Realization of chronic infections in 3\% } \\
\text { adults }\end{array}$ & [13] \\
\hline 1997 & $\begin{array}{l}\text { Validation of infectious clones in chim- } \\
\text { panzees }\end{array}$ & [13] \\
\hline 1999 & Development of HCV replicon model & [13] \\
\hline 2005 & $\begin{array}{l}\text { In vitro replication of } \mathrm{HCV} \text { in tissue } \\
\text { culture }\end{array}$ & [13] \\
\hline 2006 & $\begin{array}{l}\text { Transmission from culture to chimpan- } \\
\text { zee and back to culture }\end{array}$ & [13] \\
\hline 2000-2014 & $\begin{array}{l}\text { Era of drug development } \\
\text { Preclinical testing for HCV antivirals in } \\
\text { chimpanzees }\end{array}$ & [13] \\
\hline 2014 & $\begin{array}{l}\text { FDA approval of first curative cocktail } \\
\text { for HCV }\end{array}$ & [13] \\
\hline 2012 & $\begin{array}{l}\text { CDC recommends testing for HCV by all } \\
\text { people born in 1945-1965 in the United } \\
\text { States; First US HCV Testing Day }\end{array}$ & [14] \\
\hline
\end{tabular}

agent. ${ }^{4}$ They then collected blood samples from patients infected with unknown virus and injected it into chimpanzee, which has similar genetic makeup as that of humans, to cause infection. NANBH agents injected into the blood of this animal model multiplied, and hence, the animal was infected. ${ }^{8}$ After a number of experimental trials and study of viral transmission within the population of this animal, NANBH was found to be caused by a small enveloped agent.

In 1989, a team of scientists at Chiron Laboratories led by Michael Houghton collected blood samples from infected chimpanzee and successfully cloned a small fragment of the genome of HCV (strain HCV-1) in order to develop diagnostic tests., ${ }^{73,15}$ After this successful experiment, they tried to produce antibodies to HCV in human blood. Although infectious clones were successfully developed, tissue culture system for viral multiplication was not found. ${ }^{13}$ 
With the onset of HCV replicons developed by Lohmann et al. there was no need to clone infectious virus, and hence, this was supposed to be one of the landmark drug discoveries in the cure of HCV. This even favored RNA replication in tissue culture. ${ }^{16}$ Takaji Wakita's group isolated HCV replicon, i.e., HCV genotype 2a clone called JFH-1 from a Japanese patient with fulminant hepatitis. Scientists consider JFH-1 as the first authentic clone because of its ability to grow in cell culture. When the genome of this HCV clone was transfected into Huh-7 cells, HCV particles were generated, which were capable of infecting naïve cells and chimpanzee. ${ }^{17}$ Eventually, scientists transferred these generated HCV particles into chimpanzee for clinical trial, which gave positive result. This led to the discovery of HCV antiviral, which was finally approved by the US Food and Drug Administration in 2014. ${ }^{13}$ Since a viral agent was identified with a straightforward molecular biology approach without immunoelectron microscopy or even not undergoing replication in tissue culture, a new way to identify pathogenic agent was developed. Finally, the HCV was recognized and was found to display a similar assembly model and protein envelope as that of encephalitis flavivirus. So, the International Taxonomy Committee classified HCV in the new genus of hepaciviruses in the family of Flaviviridae. ${ }^{12}$

\section{Treatment of HCV: Current Findings and Barriers}

HCV infection and liver transplantation result in severe liver disease, often including liver cirrhosis and hepatocellular carcinoma. As defined by phylogenetic and sequence analysis of the HCV genome, the virus contains six major genotypes, varying by 30 to $35 \%$ at the nucleotide level. ${ }^{18}$ Among the six genotypes and 70 subtypes, genotype 1 is found to be the most common HCV genotype, followed by 3,2 , and $4 .{ }^{19}$

Successful treatment of HCV means eradication of the virus, thereby preventing cirrhosis and further complications, which is measured in terms of sustained virologic response (SVR). The combined use of pegylated interferon $\alpha$ (pegIFN $\alpha$ ) and ribavirin (RBV) for 24 to 48 weeks leads to higher SVR rates than does IFN monotherapy. This result has been successfully found even in patients with advanced liver disease or the patients still having HCV infection even after completion of IFN therapy. ${ }^{20}$

These drugs give different immune responses to infection, following different nonspecific pathways. Researchers have explored out the best treatment response to be in patients with genotypes 2 and 3 of HCV. 24 weeks of treatment of the patients having these genotypes with the combined therapy leads to SVR rates of approximately $80 \%$. However, even 48 weeks of combined therapy given to patients with genotype $1 \mathrm{HCV}$ gives SVR rates of approximately $40 \%$ only. So, genotype 1 is said to be the most difficult genotype to be treated. Despite ineffectiveness in some patients, the combined therapy of pegIFN $\alpha$ and RBV is difficult to tolerate. Hence, researchers focus on using therapies that can inhibit viral production and can be tolerated. This has been possible with the use of DAA drugs. ${ }^{21}$ It has been found that $90 \%$ of the patients treated with DAAs report reduction in HCV infection. Hence, this can block viral replication and slow disease progression to a large extent. Also, DAAs mainly target genotype 1 of HCV, which is difficult to treat even with combined therapy of pegIFN $\alpha$ and RBV. ${ }^{19}$ So, IFN-free DAA regimens are widely being used instead of poorly tolerated interferon (IFN)-based therapeutic regimens. This has even reduced tissue damage in patients with chronic liver disease. ${ }^{22}$

Patients with HCV infection in the liver have undergone liver transplantation to replace damaged liver due to the viral infection and exhibit SVR rates of 87 to $98 \%$ with oral DAA combination therapy. The $9.6 \mathrm{~Kb}$ genome of HCV undergoes translation into a glycoprotein that is processed into structural and non-structural proteins (NS proteins). NS proteins include NS3, NS4A, NS4B, NS5A, and NS5B. Currently approved DAA is found to target these NS proteins, including NS3-4A protease inhibitors (PI), NS5A inhibitors, and NS5B nucleot(s)ide and non-nucleoside analogues.

The vast and incredible genetic diversity of HCV presents a major challenge to the design and implementation of DAA for $\mathrm{HCV}{ }^{18}$ Shockingly, the emergence of resistance to DAA drugs has also been reported, which has been a major obstacle in the development of antiviral drugs. HCV exhibits a high rate of replication. The virus multiplies at the rate of $10^{12}$ virions produced daily. NS5B RNAdependent RNA polymerase (RdRp) accounts for viral production. Mutation in this viral enzyme leads to the emergence of resistance to DAA drugs ${ }^{21}$, as this enzyme is one of the targets of DAA drugs. ${ }^{18}$ Furthermore, patients report psychiatric illness after undergoing treatment with DAA regimens, which also represents an important barrier to HCV treatment. Also, IFN use results in adverse psychiatric effects, including irritability, mood swings, and even depression in about 21 to $58 \%$ of the patients. ${ }^{23}$

\section{Future Perspectives in HCV Treatment}

Detection of HCV infection in its early stage is a fundamental technique to avoid further complications in the viral infection. The use of molecular biomarkers helps significantly in the detection of $\mathrm{HCV}$ infection in its early stage, thereby providing greater hope in the reduction of further complications like liver cirrhosis or $\mathrm{HCC} .{ }^{24}$ For instance, the use of class I biomarkers like glycoproteins (hyaluronan, laminin), members of collagen family, collagenase and their inhibitors, and a number of cytokines associated with fibrogenic process greatly helps to determine the rate and different stages of progression of liver fibrinogenesis. ${ }^{25}$ Class I biomarkers are serum components associated with the mechanism of fibrogenesis, either as secreted matrix-related components of activated hepatic stellate cells and fibroblasts or as mediators of extracellular matrix (ECM) synthesis or turnover. ${ }^{26}$ Indirect markers help to assess the change in hepatic function. These markers mediate in evaluating the complexity in HCV infection, monitoring, diagnosing, and also assessing the prognosis of liver diseases by reporting different stages in the progression of the disease. ${ }^{27}$ Hence, noninvasive biomarker, which includes direct and indirect serum biomarkers, is a promising tool for the early prognosis, monitoring, and treatment of liver damage. However, the study and understanding of the diagnostic accuracy of these markers for the diagnosis of liver injury complexity are still insufficient. ${ }^{25}$

Handling psychiatric illness provides a better way to tackle with complications that arise by the use of DAA drugs. This can be done by increasing awareness and better understanding of $\mathrm{HCV}$ infection. Moreover, HCV undergoes mutation in NS proteins that are major targets of DAA drugs in order to develop resistance to these drugs. This can be prevented by the use of CRISPR-Cas system in editing or deleting portion of viral genome responsible for resistance. The current knowledge of molecular mechanisms of $\mathrm{HCV}$ involved in developing resistance to DAA drugs is insufficient. The better understanding of the molecular mechanisms provides novel insight into treating HCV.

\section{Conclusion}

The discovery of hepatitis $\mathrm{C}$ virus has been a long journey and a landmark in the treatment of liver diseases, including hepatitis, cirrhosis, and hepatocellular carcinoma. HCV treatment with 
combined therapy of pegIFN $\alpha$ and RBV has resulted to higher SVR, even in patients with chronic liver diseases. However, this combined therapy becomes difficult to tolerate. In this regard, DAA drugs, including protease inhibitors, solve the problem. But, there is often emergence of resistance to these drugs. Although the current knowledge of molecular mechanisms involved in developing resistance is insufficient, the relevant use of CRISPR-Cas system provides novel insights into preventing this resistance. The use of serum biomarkers helps in early diagnosis of HCV infection, thereby preventing further complications. The better understanding of molecular mechanisms involved in HCV infection provides better hope in dealing with chronic liver diseases.

\author{
Abbreviations \\ NANBH: Non-A, non-B hepatitis \\ HCV: Hepatitis $C$ virus \\ cDNA: Complementary deoxyribonucleic acid \\ DAAs: Direct-acting antivirals \\ SVR: Sustained virologic response \\ HCC: Hepatocellular carcinoma \\ CRISPR-Cas: Clustered regularly interspaced short palindromic \\ repeats-CRISPR-associated system \\ RdRp: RNA-dependent RNA polymerase \\ Ethics Approval and Consent to Participate: Not applicable \\ Consent for Publication: Not applicable
}

Availability of data and materials: All the databases used in generating the data, analyzing them, and preparing this manuscript are included in this published article.

Competing Interests: The author declares to have no competing interests.

Author's Contributions: The author singly analyzed the information, prepared a study design, read, and approved the final manuscript.

\section{References}

1. Ferri $C$, Sebastiani $M$, Giuggioli $D$, et al. Hepatitis $C$ virus syndrome: a constellation of organ- and non-organ specific autoimmune disorders, B-cell non-Hodgkin's lymphoma, and cancer. World J Hepatol 2015;7(3):327-343. DOI: 10.4254/wjh.v7.i3.327.

2. Mohamed AA, Elbedewy TA, El-Serafy $M$, et al. Hepatitis $C$ virus: a global view. World J Hepatol 2015;7(26):2676-2680. DOI: 10.4254/ wjh.v7.i26.2676.

3. Centre for Disease Control and Prevention: https://www.cdc.gov/ hepatitis/statistics/2018surveillance/HepC.htm\#Figure3.1

4. The Nobel Prize in Physiology or Medicine 2020. NobelPrize.org. Nobel Media AB 2020. Tue. 27 Oct 2020. https://www.nobelprize. org/prizes/medicine/2020/summary/.

5. Feinstone SM, Kapikian AZ, Purceli RH. Hepatitis A: detection by immune electron microscopy of a viruslike antigen associated with acute illness. Science 1973;182(4116):1026-1028. DOI: 10.1126/ science.182.4116.1026.

6. Bayer ME, Blumberg BS, Werner B. Particles associated with Australia antigen in the sera of patients with leukaemia, Down's Syndrome and hepatitis. Nature 1968;218(5146):1057-1059. DOI: 10.1038/2181057a0.
7. Bukh J. The history of hepatitis $\mathrm{C}$ virus (HCV): basic research reveals unique features in phylogeny, evolution and the viral life cycle with new perspectives for epidemic control. J Hepatol 2016;65(1 Suppl):S2-S21. DOI: 10.1016/j.jhep.2016.07.035.

8. Houghton $\mathrm{M}$. The long and winding road leading to the identification of the hepatitis C virus. J Hepatol 2009;51(5):939-948. DOI: 10.1016/j. jhep.2009.08.004.

9. Gerlich WH. Medical virology of hepatitis B: how it began and where we are now. Virol J 2013;10:239. DOI: 10.1186/1743-422X-10-239.

10. https://www.hepb.org/about-us/baruch-blumberg-md-dphil/.

11. Houghton M. Discovery of the hepatitis C virus. Liver Int 2009;29 (Suppl 1):82-88. DOI: 10.1111/j.1478-3231.2008.01925.x. PMID: 19207970.

12. Trepo C. A brief history of hepatitis milestones. Liver Int 2014;34(Suppl 1):29-37. DOI: 10.1111/liv.12409.

13. Lanford, Robert $E$ et al. The chimpanzee model of viral hepatitis: advances in understanding the immune response and treatment of viral hepatitis. ILAR J 2017;58(2):172-189. DOI: 10.1093/ilar/ilx028.

14. Ward JW. Hepatitis $C$ virus: the 25 -year journey from discovery to cure. Hepatology 2014;60(5):1479-1482. DOI: 10.1002/hep.27377. Epub 2014 Oct 2. PMID: 25131647.

15. Kato N. Molecular virology of hepatitis $C$ virus. Acta Med Okayama 2001;55(3):133-159. DOI: 10.18926/AMO/32025.

16. Lohmann V, Körner F, Koch J, et al. Replication of subgenomic hepatitis C virus RNAs in a hepatoma cell line. Science 1999;285(5424):110-113. DOI: 10.1126/science.285.5424.110.

17. Duverlie G, Czeslaw W. Cell culture systems for the hepatitis $C$ virus. World J Gastroenterol 2007;13(17):2442-2445. DOI: 10.3748/wjg.v13. i17.2442.

18. Horner SM, Naggie S. Successes and challenges on the road to cure hepatitis C. PLoS Pathog 2015;11(6):e1004854. DOI: 10.1371/journal. ppat.1004854.

19. Vermehren J, Park JS, Jacobson IM, et al. Challenges and perspectives of direct antivirals for the treatment of hepatitis $C$ virus infection. J Hepatol 2018;69(5):1178-1187. DOI: 10.1016/j.jhep.2018.07.002.

20. Rong L, Perelson AS. Treatment of hepatitis $C$ virus infection with interferon and small molecule direct antivirals: viral kinetics and modeling. Crit Rev Immunol 2010;30(2):131-148. DOI: 10.1615/ critrevimmunol.v30.i2.30.

21. Jazwinski $A B$, Muir AJ. Direct-acting antiviral medications for chronic hepatitis $C$ virus infection. Gastroenterol Hepatol (N Y) 2011;7(3):154-162.

22. Dustin LB, Bartolini B, Capobianchi MR, et al. Hepatitis C virus: life cycle in cells, infection and host response, and analysis of molecular markers influencing the outcome of infection and response to therapy. Clin Microbiol Infect 2016;22(10):826-832. DOI: 10.1016/j. cmi.2016.08.025.

23. McGowan $C E$, Fried $M W$. Barriers to hepatitis $C$ treatment. Liver Int 2012;32 Suppl 1(0 1):151-156. DOI: 10.1111/j.1478-3231.2011.02706.x.

24. Hoshida Y, Fuchs BC, Bardeesy N, et al. Pathogenesis and prevention of hepatitis $C$ virus-induced hepatocellular carcinoma. J Hepatol 2014;61(1 Suppl):S79-S90. DOI: 10.1016/j.jhep.2014.07.010.

25. Valva P, Ríos DA, De Matteo E, et al. Chronic hepatitis C virus infection: serum biomarkers in predicting liver damage. World J Gastroenterol 2016;22(4);1367-1381. DOI: 10.3748/wjg.v22.i4.1367.

26. Gressner OA, Weiskirchen R, Gressner AM, et al. Biomarkers of hepatic fibrosis, fibrogenesis and genetic pre-disposition pending between fiction and reality. J Cell Mol Med 2007;11(5):1031-1051. DOI: 10.1111/j.1582-4934.2007.00092.x.

27. Nallagangula KS, Nagaraj SK, Venkataswamy L, et al. Liver fibrosis: a compilation on the biomarkers status and their significance during disease progression. Future Sci OA 2017;4(1):FSO250. DOI: 10.4155/ fsoa-2017-0083. 